\title{
Research On" Double Eleven" College Students' Online Shopping Behavior
}

\author{
Xueping $\mathrm{Liu}^{1,2}$ \\ ${ }^{1}$ Engineering Training Center \\ Shenyang Aerospace University \\ Shenyang, China \\ ${ }^{2}$ College of Automation Engineering \\ Nanjing University of Aeronautics and Astronautics \\ Nanjing, China \\ liuxueping024@163.com
}

\begin{abstract}
As a new-style shopping, online shopping is a kind of brand new shopping concept and experience. Compared with the traditional way of consumption, it provides more convenience for the customers, especially for modern colleague students. As a special consumer group, college students are capable to accept new things, besides they have a lot of spare time, which is fragmentary. Moreover, many college campuses are far away from the business district, which limits college students shopping. So online shopping is favored by college students and makes them become the main force of online shopping.
\end{abstract}

Keywords-double eleven; colleges students online shopping; online shopping behavior; trend recommendation

\section{INTRODUCTION}

In order to study the present situation of college students online shopping and the broad space for development, this paper analyzes the factors affecting college students online shopping, involving industry, multi views to summarize the development status of college students online shopping, analyzes the main factors that affect the development of College Students' online shopping and obstacles, discussing the relationship between online shopping behavior of "double eleven" of college students and the development of electronic commerce. The main problem researched in this paper is the emergence and development of "double eleven" online shopping behavior of College students.

\section{E-COMMERCE SITUATION UNDER INTERNET FINANCE BACKGROUND}

Now online shopping has become a part of people's daily life from a fresh thing gradually, affecting people's traditional consumption habits and thinking, life style, but gradually win support of people with its special superiority. The "Thirtieth Chinese Internet Development Statistics Report" released by CNNIC shows, China netizens have reached 0.528 billion as of June, 2013; Internet penetration rate is $39.9 \%$. But the report also indicates that the netizens with bachelor's degree and above accounted for $11.5 \%$ in the education structure.

According to the survey, the main consumers of online shopping are college students. One of the reasons is the development of Internet has provided the convenience of online shopping for college students; secondly, college students like avant-garde form of consumption; thirdly, the network shopping is just to meet students' demand of " shopping without going out of home ". The Bloomberg report said China online mall launched various anomalous promotions at the beginning of the "double eleven". Taobao.com designated Nov.11 "singles day" of each year as "online shopping day" since Nov. 11, 2009, and conducted online merchandise discounts with minimum 90 percent off, which caused China netizens' active support, especially attracted college students' attention. According to the statistics of Chinese taobao.com in November 11th of last year, total sales reached $\$ 3.1$ billion, which is higher than total sales amount of two USA annual biggest online shopping day -- "black Friday" (the first day after Thanksgiving) and "cyber Monday" (the first Monday after Thanksgiving). In the period of "double eleven" online shopping, college students account for the vast majority, which has been made deep analysis by domestic and foreign well-known experts. College students' online shopping group consumption will bring great effect to the development of the "double eleven" online shopping.

\section{ANALYSIS OF “DOUBLE ELEVEN" COLLEGE STUDENTS ONLINE SHOPPING CHARACTERISTICS}

The group being investigated is the students of nearby universities located in Shenbei New Area, Shenyang, Liaoning province, including: Shenyang Aeronautics and Astronautics University, Liaoning University, Shenyang Normal University, Shenyang Institute of Engineering, Liaoning Academy of Fine Arts, Liaoning Institute of Advertising, Liaoning Transportation University. In order to improve the reliability of the data, the author used the simple random sampling method based on the stratified sampling. We issued 50 questionnaires for each college, totally 350 copies, 286 were returned, and 262 of them are valid questionnaires, the returning rate is $81.7 \%$, and the effective rate of returning is $91.6 \%$.

In the investigated college students, the proportion of male and female: male $49.3 \%$, female $50.7 \%$; grade: freshman $40.5 \%$, sophomore $31.2 \%$, junior $24.8 \%$, senior $3.5 \%$; the proportion of urban and rural students: students from rural areas $56.7 \%$, the students from cities $43.3 \%$; the 
average monthly living expenses ratio: 500 Yuan and below 13.9\%, 501-1000 Yuan 51.1\%, 1001-1500 Yuan 28\%, 1501-2000 Yuan 5.3\%, more than 2001 Yuan 1.7\%.

According to the analysis of survey data, college students online shopping behavior features can be summarize as following:

The purchased products are relatively concentrated, and online shopping amount is large

According to the survey data, we can find that in the usually purchased goods of college students from online shopping, there are three goods ranked the top three which includes clothing footwear, books and audio-video products and digital products, especially clothing footwear accounts for as high as 43\%(Figure 1). 95\% College students spend less than 500 Yuan in online shopping every month, but $93 \%$ of them only have living expense between 501 and 1000 Yuan. This indicates that despite the students have their own economic constraints, online shopping amount proportion is still large.

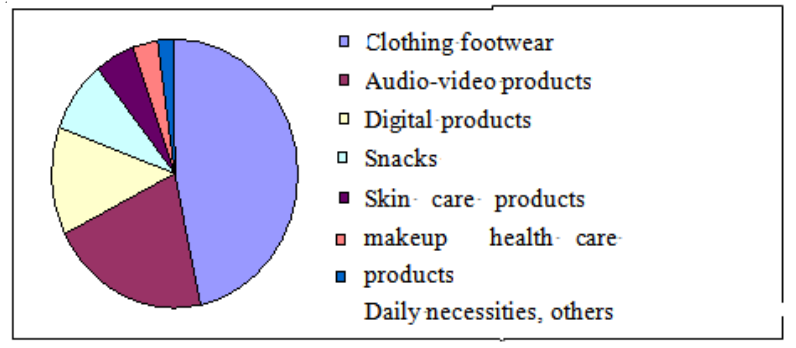

Figure 1. Ratio of college students' online shopping products categories

Taobao.com is the first choice of college students in online shopping

According to the survey data analysis, half of the students prefer taobao.com as their online shopping website, and there are many students even opening their own Taobao shops in taobao.com. When we enjoy the surprise and convenience brought by taobao.com, it is not difficult to find taobao.com has two most important successful factors: one is the secured transaction mode of AliPay provides a security guarantee; the other is freely opening shop attracts a large number of businesses and self-employed individuals entering, enriching goods species invisibly and lowering the costs, which bring a lot of consumers to taobao.com, and more of these consumers are college students.

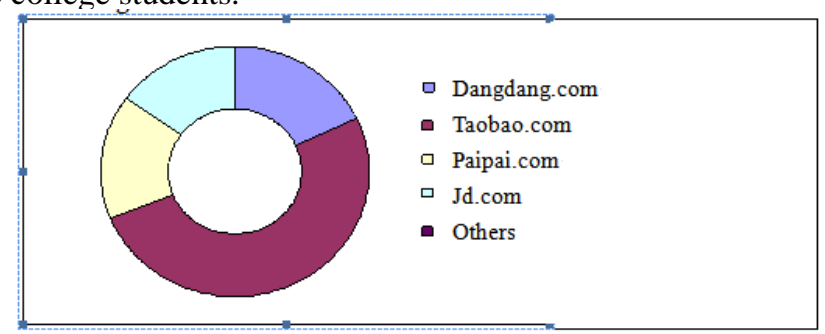

Figure 2. online shopping websites of college students

Rational consumption is the mainstream

Shi Yingling (1998) specified in the investigation and analysis of College Students' Consumption Psychology and Consumer Behavior, consumption psychology of college students has the reasonable practicability. From our data, the investigation conclude that, the quality of products is the main standard for college students to purchase in online shopping, followed by the product price and reputation, and the appearance of the product ranks the fourth. The results show that students can keep rational consumption concept in online shopping, make objective identification of product information and moderate consumption without blindly following the trend.

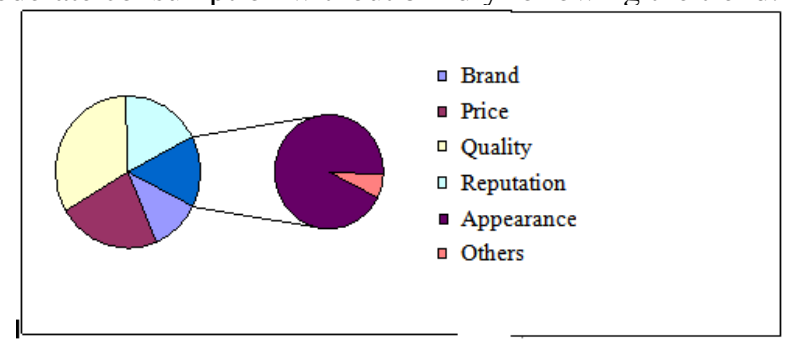

Figure 3.Main purchasing standard in online shopping

In the premise of safety, convenience is the first considered factor to select payment mode

In online shopping, how to select payment mode is an unavoidable issue. In the survey data, $45 \%$ college students select AliPay, 37\% select e-bank and 12\% prefer paying on delivery. AliPay is a third party payment platform and its secured transaction mode provides security assurance for both parties. Also, AliPay links up with most websites. Therefore, it becomes the first choice of college students.

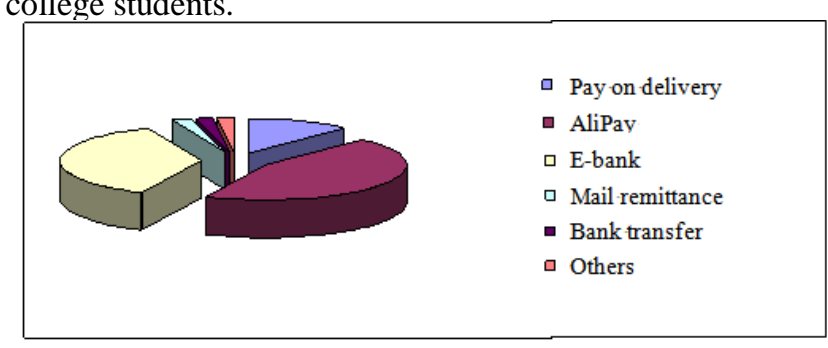

Figure 4.Payment mode selection of online shopping

\section{Express selection}

When shopping online, express company is the most commonly used method of delivery, accounting for $84 \%$ of the respondents. Including STO, Yuantong express, Zhongtong express, the Daily express, Yunda Express has become the main way of distribution, especially STO and Yuantong Express account for more than half of all express. And the choice of EMS is less, accounting for $14.7 \%$. Wherever the expresses cannot reach, people will choose the post office.

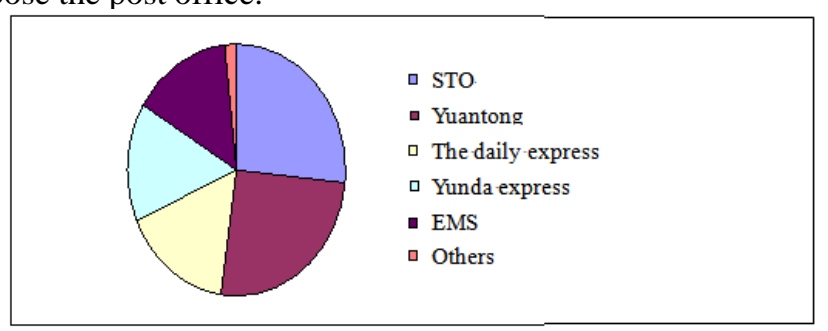

Figure 5.Express selection of college students online shopping

Evaluation after online shopping

The investigation shows that $0 \%$ of college students select "very poor" evaluation after online shopping, $4.3 \%$ of the students select "poor", 7.2\% of the students select "general", $28.7 \%$ of the students select "good" and $3.2 \%$ of 
the students select "very good". In order to reflect more objectively, please see the following Fig.

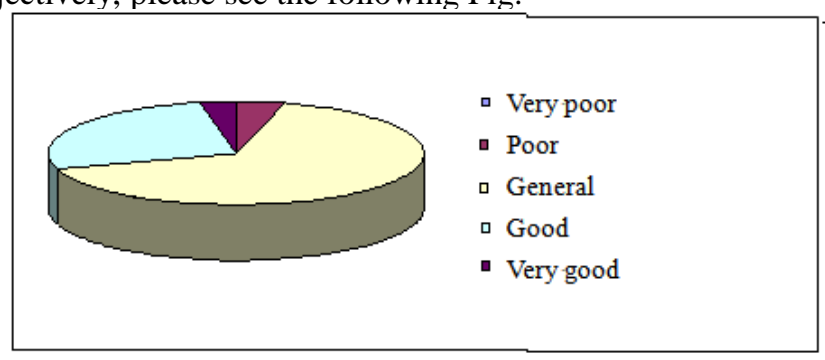

Figure 6. The evaluation after online shopping

\section{THE INFLUENCE FACTORS THAT "DOUBLE ELEVEN" PROMOTING COLLEGE STUDENTS ONLINE SHOPPING}

A. Underlying causes to promote college students online shopping

\section{1) active thought, easy to accept new things}

In wonderful campus, college students group have active thought and rich spitrit of adventure. They are curious of new things. As a new shopping mode, online shopping is different with traditional shopping, satisfying the students' consumer psychology to pursue newness.

2) Having a certain of risk perception and able to avoid risk

The perceived risk theory is mainly to consider consumer behavior as a risk taking behavior, because when consumers consider to purchase products, and cannot determine the results of using the products, so consumers actually take a risk. The investigation shows that $88.3 \%$ online shopping groups worry about the quality of goods, $36.8 \%$ people worry about website trust problems, $29.4 \%$ people worry about the payment security, $24.2 \%$ people worry about personal information security. When they meet online shopping problems, $46.7 \%$ people will choose to contact customer service to help with a replacement or return, $29.8 \%$ people attribute it bad luck, $13.6 \%$ people will choose no matter and pay more attention next time. College students consumption group belongs to high knowledge group, compared with other consumer groups, having learned relevant risk knowledge, and they are eager to show and more likely to accept this consumption mode.

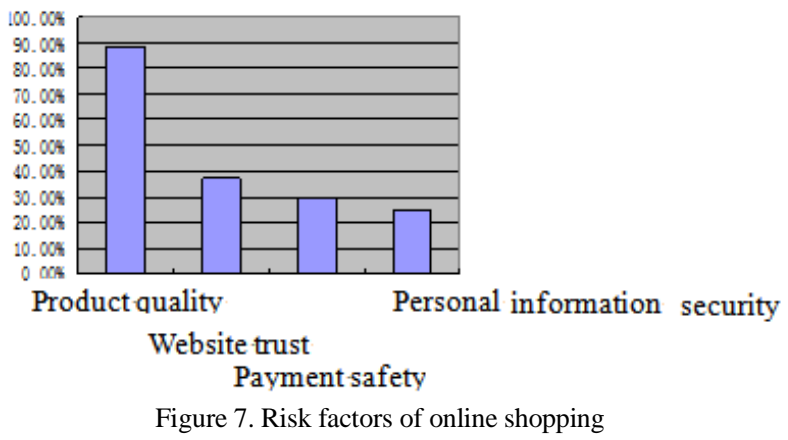

Figure 7. Risk factors of online shopping

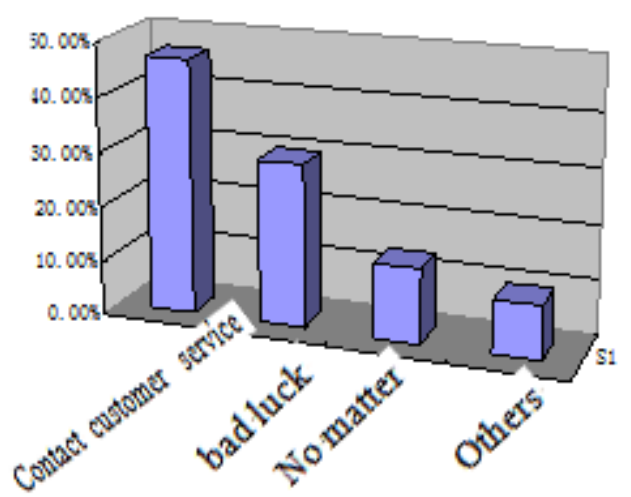

Figure 8. Solutions for the problems occurring in online shopping

\section{B. External causes promoting college students online} shopping

1) Obvious group consumption feature, easy to form blind compare psychology

The investigation shows college students' online shopping sites are concentrated in the dormitory, home. There is a security risk, so the students tended to choose relatively safe network environment. Consumer culture in dormitory penetrates to the life of each member, and affects everyone's consumption psychology and consumer behavior. In order to keep consistent with the group, they will imitate each other, even compare, then some people will appear blind consumer behaviors. Purchase behavior is mainly determined by the purchase intention, attitude is one of the factors that determining the intention. When group members tend to the same attitude, it will stimulate the purchase behavior of individual. "Double eleven" is the online shopping boom, consumer groups of college students are more likely to have slavish psychology.

2) Fast pace of life, pursuing convenient and swift

As the new youth in new century, the requirements of life taste are relatively high, but because of the academic, social, growing pressure, they pay more attention to pursue quick and stimulating consumption. Compared with the traditional shopping time-consuming mode, online shopping avoids these complicated process, with clicking mouse, you canyou're your favorite goods, which is in accordance with the living habits of these young people, so that more students throw the olive branch to it. "Double eleven" is a competition opportunity of the sellers, they enhance their competitiveness by improving the delivery speed. The rapid development of logistics industry has made great contribution to the "double eleven" college students online shopping.

3) Single source of finance, pursuing cheap and fine

Most of college students' economy is not independent, and their main source of income is from parental support, so they are relatively sensitive to the price. Therefore, price of goods have become the focus of them. Online sales eliminates a variety of shop rent, staff wages and so on in traditional sales, so the cost of sales is relatively low, which cater to the pursuit of high quality and inexpensive consumer psychology of college students. In "double eleven" period, in addition to playing time, the businesses also attend the most important price war. The main reason that students choosing online shopping partly because online shopping is cheap that can adapt to the college students' consumption patterns. 


\section{MARKETING STRATEGY ON COLLEGE STUDENTS' ONLINE SHOPPING}

\section{A. Focus on products and service quality}

College students group have a lot of ways to achieve online shopping information. They pay attention to wordof-mouth marketing and search marketing, at first through the picture information, text description to learn the corresponding goods. They pay more attention to the third party evaluation, which prompts business pay attention to the description of the goods in conformity with the facts, not exaggerated propaganda or distortion in advertising campaigns. At the same time, businesses should strive to improve the quality of service. Businesses try to make every customer satisfied, build good customer relationship, be sincere, caring and all for the sake of the customer, taking the customer in mind, giving God warm service, ensuring the quality of products and logistics distribution, to effectively attract and develop potential consumers. Only such businesses can win the public praise and gain benefits and long-term development.

B. Multi channel and flexible payment methods, improving the efficiency of logistics distribution

College students are familiar with electronic technology, making them more inclined to fast, convenient in shopping process. While the online business focuses on building a network platform, do not ignore the establishment of mobile phone service client. Building flexible payment channel for consumers is also a service improvement. In addition, logistics distribution time will directly affect the consumers' overall satisfaction to businesses. Selecting logistics with good service quality, delivery of high efficiency will increase consumers' satisfaction, but also one of the ways to cultivate customer loyalty. Businesses need to strengthen laws and regulations construction of related network shopping, improving relevant system and rectifying the virtual social order and discipline.

\section{Improve the consciousness of rights safeguarding of college students online shopping, decreasing the cost in safeguarding their rights}

In the online shopping, college students should not only be familiar with the process, but should pay more attention to improve their awareness of rights. For example, learn how to identify the authenticity of online stores, service quality. Learn to query the seller's credit, make careful analysis of the products with supernormal lower price. For high transaction, it's better to choose the third party payment and ask for a receipt or certificate from the seller, safekeeping the remittance, while preserving the mails with sellers, to prepare for possible need. In this way, once problem exists, it will be conducive to safeguard the legitimate rights and interests of consumers.

\section{Optimize colleges' consumer culture}

With the development of society, the consumption concept is also gradually changing. In order to build harmonious society, we also continue to put forward a variety of new, more correct consumption concept, such as "green consumption". College students should develop good habits, opposing extravagance and waste, promoting moderate consumption; against aestheticism (only focus on the appearance of merchandise and ignore the practicality and durability), claiming practical consumption; against the negative attitude, advocating to safeguard consumption.

\section{E. Build exclusive platform}

According to the survey data, $87 \%$ students want to have a specific professional shopping platform for them. Unfortunately, there is no such a special network shopping platform for college students in current market. It can be imagined that if a business launches such a professional platform, it will be very popular. To build a network shopping platform for college students, we can learn from other outstanding network platform model. For example, 58.com has area classification function, so college students' online shopping platform can make classification according to colleges, on which based to build barter area second-hand market, free shipping module in the same college (for instance we can use renren.com for reference, to build community service for college students online shopping platform (in addition, to build major service module according to the different majors, for example system reinstallation, professional guidance, paper polish etc.)).

\section{CONCLUSION}

College students' consumption psychology is full of personality, and is easily influenced by herd mentality, with strong ability to accept new things. Our college students are mostly born in 1980s and 1990s, growing up with the development of Internet. According to the analysis, the author collected and analyzed data by distributing questionnaires to surrounding colleges to understand and grasp basic characteristics of "double eleven" college students online shopping. They have outstanding personality and are very sensitive to new things. The paper starts with the online shopping behavior to explore its advantages and disadvantages, and find solutions, and put forward reasonable proposals. In my opinion, the study has great practical significance.

\section{REFERENCES}

[1] Lv Jing, Lv Huining. China's Online Shopping Development Situation, Problems and Countermeasures [J].Shanxi Agricultural Science, 2013

[2] Zhang Yurong. Survey Report on College Students' Condition of Consumption [J]. Ideological Education Research

[3] Zhang Xuebo, Liu Jing, Lin Xiuyu•Research Method and Practice of Communication [M] Beijing: Beijing University Press 2013

[4] Schiffman, Kaniuke. Consumer Behavior [M]. Yu Wenzhao translation 7 edition. Shanghai: East China Normal University Press, 2012

[5] Cui Min, Zhang Guanwen •Research on College Students Online Shopping Behavior [G] Shandong University, 2012

[6] Yi Xing, Research of China's Network Consumption Theory and Practice [D] Wuhan: Huazhong Normal University 2013

[7] Huang Shan, Liu Yue. Consumer Online Behavior Analysis and Countermeasures [J]. Value Engineering, 2013

[8] [8] Hao Wenjuan, Guo Wangjuan. Survey Analysis of College Students' Online Shopping Behavior and Psychological Characteristics [J]. Journal of Jiaxing University, 2011

[9] Zheng Yan. Research Overview of Online Shopping Behavior [J]. Trade Observation, 2012

[10] Xu Haobo. Consumer Behavior Research under Virtual World Environment, [J]. Economist, 2010 
[11] Hu Zichao. Influence Factors Analysis of Online Shopping Behavior [J]. Science and Technology, 2013

[12] Gao Tiemei. The Method of Econometric Analysis and Modeling [J]. Beijing: Tsinghua University Press, 2013

[13] Li Zinai, Pan Wenqing. Quantitative Economics [J]. Beijing: Higher Education Press, 2011

[14] Zhang Wenchao, Consumption Value Research of College Students under the Background of Globalization [J].Thought. Theory. Education, 2013
[15] Li Yan. Thought of Contemporary College Students' Consumption Value [J]. Tianjin Manager College Journal, 2012

[16] Laily Hj.Paim.Students'Online Shopping Behavior:An EmpiricalStudy,Journal of American Science,2010,6

[17] TokuroMatsao,Takayuik to,and Tormatsa Shin-tain. A VolumeDiscount-Based Allocation Mechanism in Group Buying.Computer society, 20 